六方晶 $\mathrm{W}$ 型フェライト $\mathrm{Sr}_{1-\mathrm{x}} \mathrm{Ba}_{\mathbf{x}}\left[\mathrm{ZnLi}_{0.5} \mathrm{Fe}_{0.5}\right] \mathrm{Fe}_{16} \mathrm{O}_{27}$ の結晶安定性と磁気特性

諏訪建一郎, 田口 壬, 武石卓

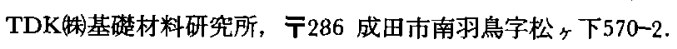

\title{
Crystal Stability and Magnetic Properties of W-type Hexagonal Ferrite $\mathrm{Sr}_{1-\mathrm{x}} \mathrm{Ba}_{\mathbf{x}}\left[\mathrm{ZnLi}_{0.5} \mathrm{Fe}_{0.5}\right] \mathrm{Fe}_{16} \mathrm{O}_{27}$
}

\author{
Kenichiro Suwa, Hitoshi Taguchi and Taku Takeishi \\ Materials Research Center, TDK Corporation, 570-2 Aza-matsugashita Minami-hadori, Narita 286.
}

Received March 8, 1996

SYNOPSIS

Crystal stability and possibility as an anisotropic permanent magnet of W-type hexagonal ferrite with composition of $\mathrm{Sr}_{1-x B a x}\left[\mathrm{ZnLi}_{0.5} \mathrm{Fe}_{0.5}\right] \mathrm{Fe}_{16} \mathrm{O}_{27}$ was investigated. In this study, we found that the amount of $\mathrm{Fe}^{2+}$ in the calcined compound gradually increases with increasing $\mathrm{Sr}$. In the ball-milled compound followed by annealing at $900-1100^{\circ} \mathrm{C}, \mathrm{W}$ phase of $\mathrm{Sr}[\mathrm{ZnLi} 0.5 \mathrm{Fe} 0.5]$ - $\mathrm{Fe}_{16} \mathrm{O}_{27}$ partially decomposed into $\mathrm{M}$ phase and spinel phase. On the other hand, $\mathrm{Ba}$ [ZnLio.5Fe.5] $\mathrm{Fe}_{16} \mathrm{O}_{27}$ remained a single phase. It can be assumed that $\mathrm{Fe}^{2+}$ substituted for $\left(\mathrm{Li}^{+}{ }_{0.5}+\mathrm{Fe}^{3+}{ }_{0.5}\right)$ or $\mathrm{Zn}^{2+}$, and oxidation such as $\mathrm{Fe}^{2+} \rightarrow \mathrm{Fe}^{3+}$ givies rise to decomposition.

The grain size of $\mathrm{Sr}[\mathrm{ZnLi} 0.5 \mathrm{Fe} 0.5] \mathrm{Fe}_{16} \mathrm{O}_{27}$ and $\mathrm{Ba}$ [ZnLio.5 Fe.5] $\mathrm{Fe}_{16} \mathrm{O}_{27}$ sintered at $1175-1225{ }^{\circ} \mathrm{C}$, respectively, was $0.3-5.0 \mu \mathrm{m}$, their coercivity was less than $1000 \mathrm{Oe}$, and anisotropy energy (KA) and anisotropy field $\left(\mathrm{H}_{\mathrm{A}}\right)$ were estimated with about $60 \%$ of those of M-type ferrite. In conclusion, a preparation method of ferrite magnet hgaving more finer grains is necessitated for the practical use.

KEY HORD

W-type, hexagonal ferrite, $\mathrm{Sr}_{1} \times \mathrm{Bax}\left[\mathrm{ZnLi0.5} \mathrm{Fe}_{0.5}\right] \mathrm{Fe}_{16} \mathrm{O}_{27}$, anisotropic permanent magnet, phase decomposition,

\section{1 緒 咅}

現在,主に工業化されているフェライト磁石はマグ ネトプランバイト型（M型）結晶構造を有する $\mathrm{SrFe}_{12} \mathrm{O}_{19}$ 及び $\mathrm{BaFe}_{12} \mathrm{O}_{19}$ である. (以下 $\mathrm{Sr} M, \mathrm{Ba} M$ ) この中で $\operatorname{Sr} M$ 焼結磁石の飽和磁化の理論值は 4650 Gauss とされている1).

著者らの一人は, 粉砕歪みの導入, 界面活性剤添加 による微粒子高分散技術を用いて
$\mathrm{Br}=4400$ Gauss, $\mathrm{H}_{\mathrm{CJ}}=4000 \mathrm{Oe}, \mathrm{Br} / 4 \pi \mathrm{Is} \doteqdot 98 \%$, 焼 結密度 $\fallingdotseq 98 \%$ の特性を有する高性能 $\mathrm{Sr}$ フェライト焼 結磁石の開発に成功した ${ }^{2-3)}$. 次により高 $\mathrm{Br}$ 化を図 るとするなら，配向度と密度はこのように極限に近 い值である事から，M型フェライトではこれ以上の 高特性化は困難であると予想され, さらに高い飽和磁 化を持つ結晶構造のフェライト磁石の開発が必要と 考えられる.

1996年 8 月 
1980 年, Lotgering 等によって, W型結晶構造を 有するフェライト磁石には高 Br 化の可能性がある事 が示されたい。それによると，W型 Ba フェライト $\left(\mathrm{BaFe}^{2+}{ }_{2} \mathrm{Fe}_{16} \mathrm{O}_{27}\right)$ は $\mathrm{M}$ 型 $\mathrm{Ba}$ フェライトに比べ, 飽 和磁化が $10 \%$ 高く, 異方性磁界はほほ同等であると 報告された。しかし，複雑な雲囲気制御を必要とする 為, 現在工業化には至っていない。

その後, 多くの研究者により $\mathrm{Fe}^{2+を}$ 様々な元素で置 換する試みが行われてきた。.J.Magnot等は

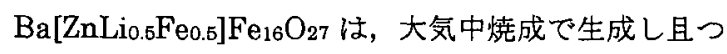
M型に近いキュリー温度と $10 \%$ 以上高い飽和磁化を 有すると報告した ${ }^{5)}$. S.Ram 等は $\mathrm{Sr}[\mathrm{ZnLi} 0.5 \mathrm{Fe}$ 0.5]・ $\mathrm{Fe}_{16} \mathrm{O}_{27}$ について同梯の報告をしだ)。しかし，これら の報告は粉体磁気特性を中心とするもので，実際の巽 方性焼結磁石に関する報告は少ない，さらに S.Ram 等は $\mathrm{Sr}\left[\mathrm{ZnLi0.5} \mathrm{Fe}_{0.5}\right] \mathrm{Fe}_{16} \mathrm{O}_{27}$ は粉砕後に相分解 (W 相 $\rightarrow \mathrm{M}$ 相十スピネル相) する事に触れているが，その詳 細は明らかでない。本研究では, $\mathrm{Ba}\left[\mathrm{ZnLi0.5} \mathrm{Fe}_{0.5}\right] \mathrm{Fe}_{16}$ - $\mathrm{O}_{27}, \mathrm{Sr}[\mathrm{ZnLi0.5} \mathrm{Fe} 0.5] \mathrm{Fe}_{16} \mathrm{O}_{27}$ 及びそれらの固溶体に 関して焼結体の磁気特性上相分解の原因についての 検討を行った。

本論文では, $\mathrm{Ba}[\mathrm{ZnLi} 0.5 \mathrm{Fe} 0.6] \mathrm{Fe}_{16} \mathrm{O}_{27}$ を $\mathrm{BaZnLiFe}$

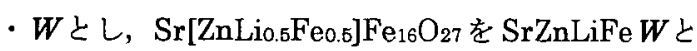
略記する.

\section{2 实験方法}

Fig.1 は本研究における実験プロセスを示す. 出発原 料として, 工業用 $\mathrm{SrCO}_{3}, \mathrm{BaCO}_{3} 、 \mathrm{ZnO}, \mathrm{Fe}_{2} \mathrm{O}_{3}$, 特 級試薬 $\mathrm{Li}_{2} \mathrm{CO}_{3}$ を用いた。これら材料を $\mathrm{Sr}_{1} \cdot \mathrm{xBax}$

- $\left[\mathrm{ZnLi0.5Fe} \mathrm{Fe}_{0.5}\right] \mathrm{Fe}_{16} \mathrm{O}_{27}(\mathrm{X}=0,0.25,0.5,0.75,1)$ に なるように秤量し, IPA (イソプロピルアルコール) 中にてアトライター混合した. その後自然乾燥, 仮プ レスを行い, 電気炬にて大気中 $1300^{\circ} \mathrm{C} て ゙ 1$ 時間仮焼 成を行った. 得られた仮焼結体に対して $\mathrm{SiO}_{2} 0.6 \mathrm{wt} \%$ と $\mathrm{CaCO}_{3} \quad 1.4 \mathrm{wt} \%$ を添加し, 乾式振動型ロッドミル にて粉碎を行った後，この粉体に対しオレイン酸 $1.3 \mathrm{wt} \%$ を添加し，さらにキシレン中でボールミル粉 砕を行った. 得られたスラリーを約 $10 \mathrm{kOe}$ の磁界中 で湿式成形を行った。これら成形体を焼結温度

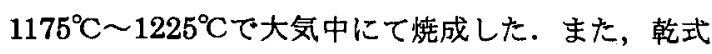
粉砕後の粉体の一部を大気中にてアニールを行っ た.

評伍は次のように行った. 仮焼成後のサンプルは振 動試料型磁力計 (VSM) を用い, 最大約 $20 \mathrm{kOe}$ 中で
単位重量あたりの飽和磁化（ $\sigma \mathrm{s} ）$ 及び $\mathrm{HCJ}_{\mathrm{CJ}}$ を測定し た. $\sigma$ sは得られたヒステリシスループより，飽和漸 近則を用い算出七た．また，X線回折及びキュリー温 度(Tc)を測定することにより結晶相を同定した。乾式 粉砕後アニールを行ったサンプルに対しては，さらに 酸化還元滴定により $\mathrm{Fe} \mathrm{e}^{2+}$ の定量化を行った. 焼結 体の磁気異方性定数 $\mathrm{K}_{\mathrm{A}}$ はトルク磁力計を用い, 10, $12 ， 15 ， 20 \mathrm{kOe}$ の各磁界で得られたトルク曲線をつ ーリエ解析し，その 2 日成分をアレニウスプロットす る事で求めた ${ }^{7)}$. 異方性磁界 $\mathrm{H}_{\mathrm{A}}$ は $2 \mathrm{~K}_{\mathrm{A}} / \mathrm{Is}$ より計算し て求めた. その他, X線回折, 熱磁気特性 $(\sigma-\mathrm{T}$ 曲 線)による相同定を行った.

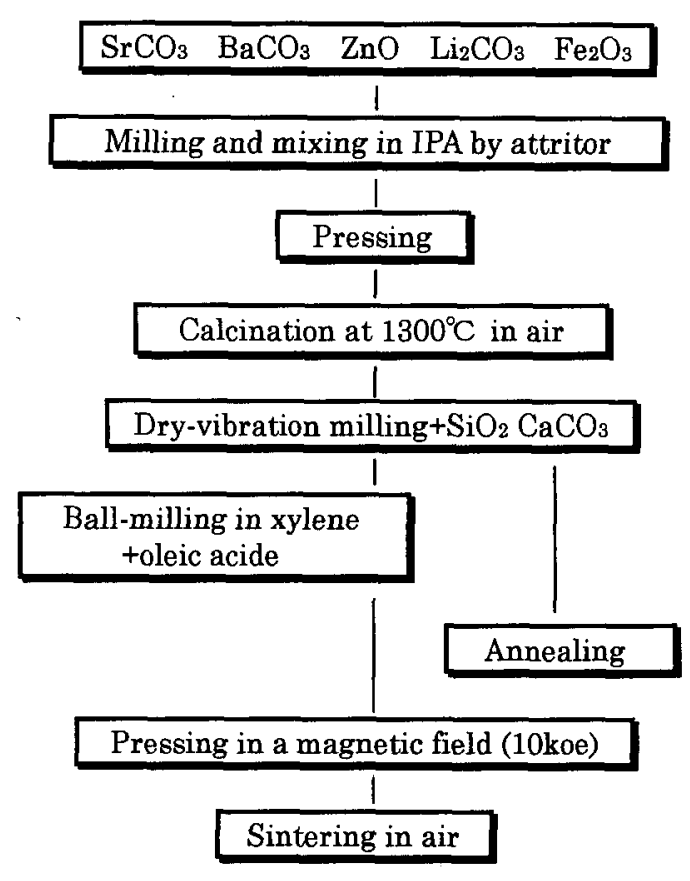

Fig.1 Producting process of $\mathrm{Sr}_{1} \cdot \mathrm{xBaxZnLiFe} W$.

\section{1 仮焼成体の評価}

\section{3 英呤結果及び考察}

Fig.2 は Sr に対する Ba の割合をX とした時の, 仮焼成体単位重量あたりの飽和磁化（ $\sigma \mathrm{s} ）$ 及び $\mathrm{H}_{\mathrm{CJ}}$ $\mathrm{X}$ 值との関係を示す.また, $\mathrm{Ba}$ と $\mathrm{Sr}$ の原子量の違い

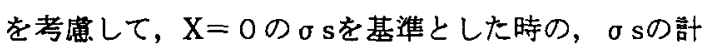
算值を同時に示す， $\sigma$ s法 Ba 量の増加に従ってわず かに低下する傾向を示した. H CJは各X值とも $100 \mathrm{Oe}$ 前後であった．X線回折から各 X 值ともW単相であ 
り， った. Fig.3 はX 值とキュリー温度との関係を示す. キュリー温度はBaの割合が增加するに従って低下傾 向を示した.

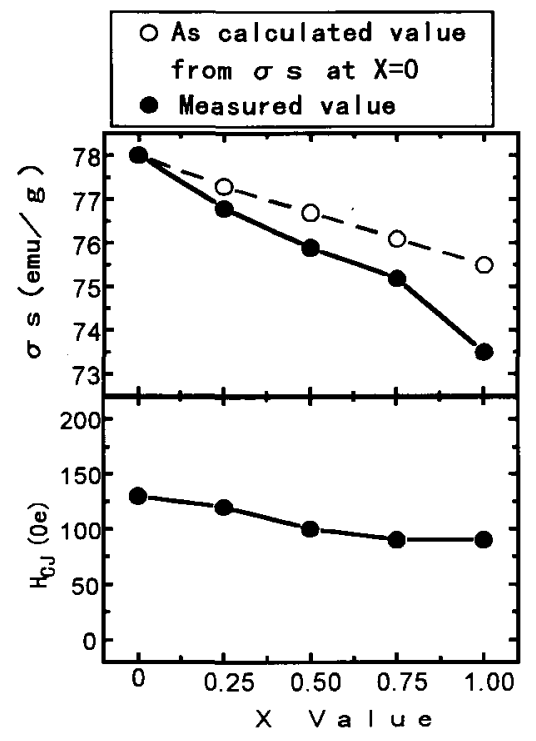

Fig.2 Dependence of $\sigma \mathrm{s}$ and $\mathrm{H}_{\mathrm{CJ}}$ on $\mathrm{X}$ value in $\mathrm{Sr}_{1 \cdot \mathrm{xBax} \mathrm{ZnLiFe} W}$ after calcining at $1300^{\circ} \mathrm{C}$ in air.

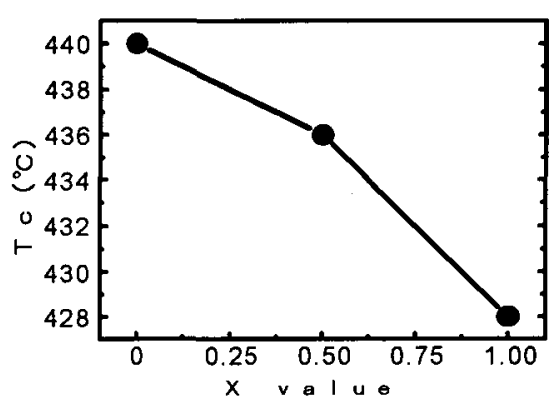

Fig.3 Dependence of curie point on $\mathrm{X}$ value in $\mathrm{Sr}_{1-\mathrm{xBax}} \mathrm{ZnLiFe} W$ after calcining at $1300^{\circ} \mathrm{C}$ in air.

\section{2 乾式粉砕後アニールによる変化}

3. Fig.4 は乾式粉砕後アニールを行った粉体につい

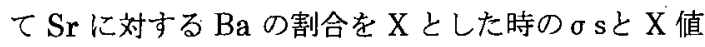
との関係を示す. 全てのアニール温度で, $\mathrm{X}=0.75$ の 時最高值を示し,アニール温度が上昇するに従い仮焼成材 のosに近づいた.

Fig.5 は乾式粉砕後, X 值とアニールを行った粉体 の $\mathrm{H}_{\mathrm{CJ}}$ の関係を示す. 各アニール温度とも $\mathrm{X}$ 值が増 加するに従い減少傾向を示し, 各 $\mathrm{X}$ 值共アニール温 度 $1000^{\circ} \mathrm{C}$ で最高值を示した。
Fig. 6 は焼成温度 $1100^{\circ} \mathrm{C}, \mathrm{X}=0,0.5,1.0$ の 線 回折パターンを示す. $\mathrm{X}=0.51 .0$ ではW 単相であった が， $\mathrm{X}=0$ では W 相と. $\mathrm{M}$ 相との混相状態であった.

Fig. 7 は $300^{\circ} \mathrm{C} \sim 500^{\circ} \mathrm{C}$ 間の $\sigma$ - $\mathrm{T}$ 曲線を示す. $\mathrm{X}=0$ においては、キュリー温度は $426^{\circ} \mathrm{Cだけであったが,}$ $\mathrm{X}=0.5$ では $434^{\circ} \mathrm{C} と 458^{\circ} \mathrm{C}, \mathrm{X}=1.0$ では $435^{\circ} \mathrm{C}, 460^{\circ} \mathrm{C}$ 及び $500^{\circ} \mathrm{C}$ 以の点というように複数のキュリー温

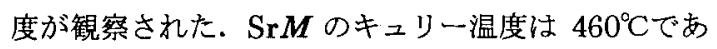
り, $\mathrm{Ba} M$ は $450^{\circ} \mathrm{C}$ である事から， $\mathrm{X}=0.5$ で $\mathrm{M}$ 相と $\mathrm{W}$ 相の混相, $\mathrm{X}=0$ では $\mathrm{M}$ 相, $\mathrm{W}$ 相, スピネル相の混相 と推定される。このように Srを多く含むW型フェう イトの場合に，W 相 $\rightarrow \mathrm{M}$ 相十スピネル相の相分解が 起き易い事がわかった。

Fig.8 は SrZnLiFe $W$ の仮焼成体, 乾式粉砕後の粉 体及び BaZnLiFe $W$ の乾式粉砕後の粉体のX 線回折 パターンを示す. SrZnLiFe $W$ の回折線は $\mathrm{BaZnLiFe} W$ と比較してかなりブロード化している 事から，乾式粉砕による結晶歪みに大きな違いがある 事が予想された。

Fig. 9 は仮焼成体の全 $\mathrm{Fe}$ に対する $\mathrm{Fe}^{2+}$ 量の $\mathrm{X}$ 值 依存性を示す， $\mathrm{X}=1.0$ において $0.2 \mathrm{wt} \%$ の最低值を示 し，X 值が減少するに従い, $\mathrm{Fe}^{2+}$ 量の増加傾向を示し た. 特に X=0.75 と 0.5 で大きな差がある事がわかっ た。

SrZnLiFe $W$ の場合だけ，乾式粉砕後のアニール時 に相分解が生じる原因を明確にする為には, 今後更に 詳細な解析が必要であるが，上記の粉砕歪みや $\mathrm{Fe}^{2+}$ の存在が関与している事が推察される.

As calcined at $1300^{\circ} \mathrm{C}$

$\square$ Dry-vibration millingtannealed at $900^{\circ} \mathrm{C}$

O Dry-vibration millingtannealed at $1000^{\circ} \mathrm{C}$

$\triangle$ Drv-vibration mill ingt annealed at $1100^{\circ} \mathrm{C}$

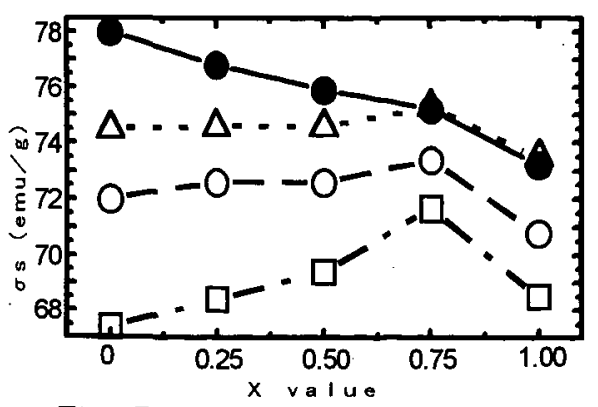

Fig.4 Dependence of saturation magnetization ( $\sigma s$ ) on $\mathrm{X}$ value in $\mathrm{Sr}_{1 \cdot x B a x Z n L i F e} W$ after dry. vibration milling and annealing. 
$\square$ Dry-vibration milling+annealed at $900^{\circ} \mathrm{C}$ Dry-vibration millingtannealed at $1000^{\circ} \mathrm{C}$
$\triangle$ Dry-vibration millingtannealed at $1100^{\circ} \mathrm{C}$

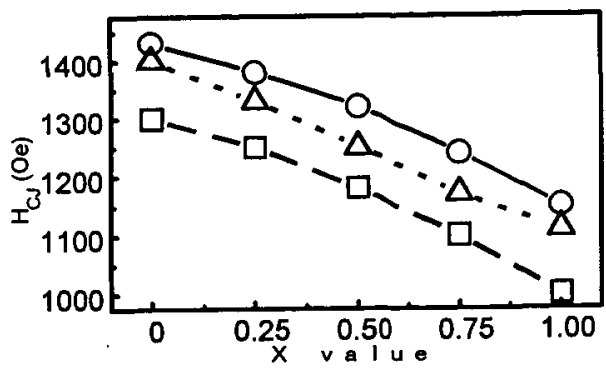

Fig.5 Dependence of coercive force on X value in $\mathrm{Sr}_{1 \cdot \mathrm{xBax} \mathrm{ZnLiFe} W}$ after dry-vibration milling and annealing.

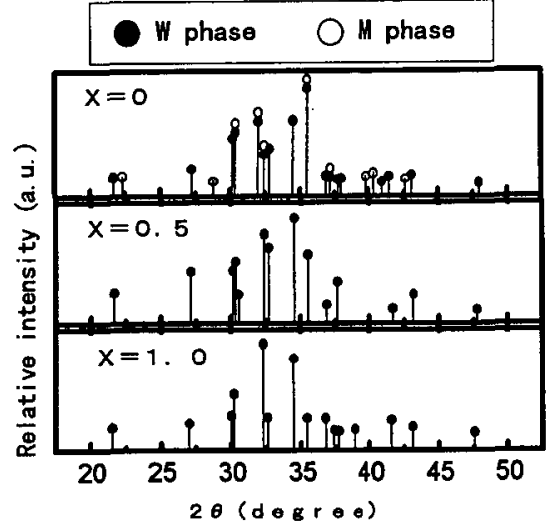

Fig.6 X-ray diffraction patterns of Sr1.xBaxZnLiFe $W$ after dry-vibration milling and annealing at $1100^{\circ} \mathrm{C}$ in air.

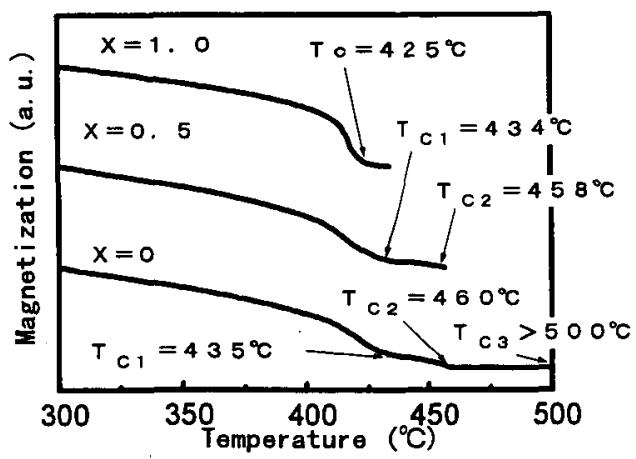

Fig. 7 o -T curves at magnetic field(500e) for $\mathrm{Sr}$ 1.xBaxZnLiFe $W$ after dry-vibration milling and annealing at $1100^{\circ} \mathrm{C}$ in air.

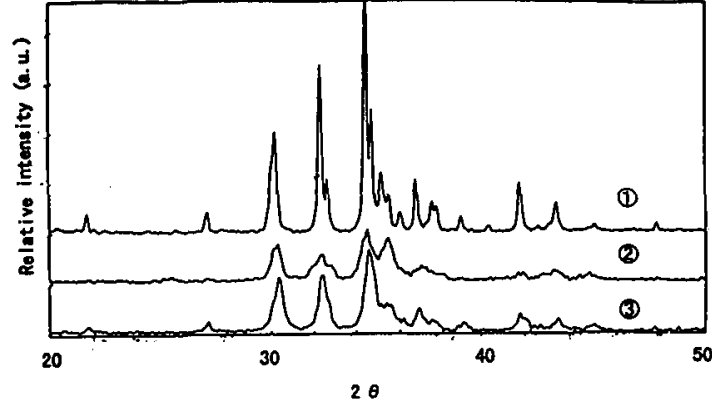

(1) $\mathrm{SrZnLiFe} W$ calcined at $1300^{\circ} \mathrm{C}$

(2) SrZnLiFe $W$ after dry-vibration milling

(3) BaZnLiFe $W$ after dry-vibration milling

Fig.8 X-ray diffraction patterns of

Sr1.xBaxZnLiFe $W$ after

dry-vibration milling.

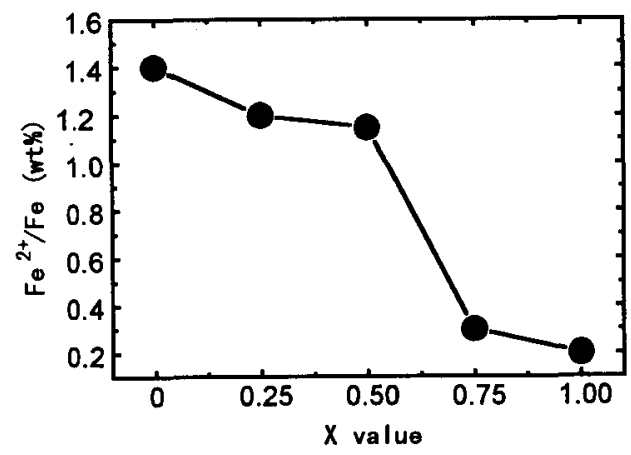

Fig.9 Dependence of $\mathrm{Fe}^{2+} / \mathrm{Fe}$ (wt\%) on $\mathrm{X}$ value in $\mathrm{Sr}_{1} \cdot \mathrm{XBaxZnLiFe} W$ after calcining at $1300^{\circ} \mathrm{C}$

\section{3 焼結体の評価}

Fig.10 は SrZnLiFe $W$ と BaZnLiFe $W$ の焼結体磁 気特性を示す $\mathrm{BaZnLiFe} W$ の場合は， $4 \pi$ Is で最大 4750Gauss, Br で 4600Gauss というM型フェライト を超える高い磁気特性が得られた。これに対して SrZnLiFe $W$ の場合は， $4 \pi$ Is で 100 300Gauss 低 く, Br では 300〜600Gauss も低い值となった。配向 度 (Br/4 $\pi \mathrm{Is})$ は, $\mathrm{BaZnLiFe} W$ で $95 \%$ 以上の值が 得られたのに対して, SrZnLiFeWでは 91\%程度と， 大きな違いが生じた.一方 Hasは逆に SrZnLiFeWで 最大 10000 eを示し, BaZnLiFe $W$ よりも2000e 程 高い值を示した。

Table2 はトルク磁力計による異方性定数 $\left(\mathrm{K}_{\mathrm{A}}\right)$ と 異方性磁界 $\left(\mathrm{H}_{\mathrm{A}}\right)$ の測定結果を示す. $\mathrm{Sr} M$ と $\mathrm{Ba} M$ 
の異方性は文献值 ${ }^{8)}$ と一致した. $\mathrm{SrZnLiFe} W$ の異方 性は BaZnLiFe $W$ の場合よりも，10２0\%大きい事 がわかった。しかし，M型に比べると約 $60 \%$ 程度の

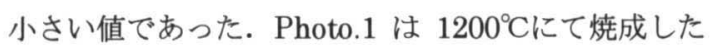
焼結体の SEM 像を示す. SrZnLiFe $W$ は 0.3 3 $\mu \mathrm{m}, \mathrm{BaZnLiFe} \boldsymbol{W}$ は 0.3〜 $5.3 \mu \mathrm{m}$ の粗大粒子を含む 不均一な粒子で構成されていた.これら実験結果はM 型と比較して HCJ が低い原因と考えられる.

Table 3 は $1200^{\circ} \mathrm{C} に て$ 焼結した焼結体の X 線回折及 びキュリー温度測定の結果を示す. BaZnLiFe $W$ は W単相であったが, SrZnLiFe $W$ は乾式粉砕した粉体 をアニールした場合と同様 $\mathrm{M}$ 相, $\mathrm{W}$ 相，スピネル相の 混相状態であった.

$\mathrm{SrZnLiFe} W$ $\boldsymbol{B r} / 4 \pi \mathrm{Is}$ が低かった原因として次の 事が推察される.

1) SrZnLiFe $W$ の乾式粉砕材は, Fig.8 が示すよう に結晶歪みが大きい為, 磁界中湿式成形段階での粒子 配向度が低下した.

2) SrZnLiFe $W$ 焼結体はW相，M相，スピネル相と の混相であるが, 生成したスピネル相がソフト相であ る為に Br が低下した.

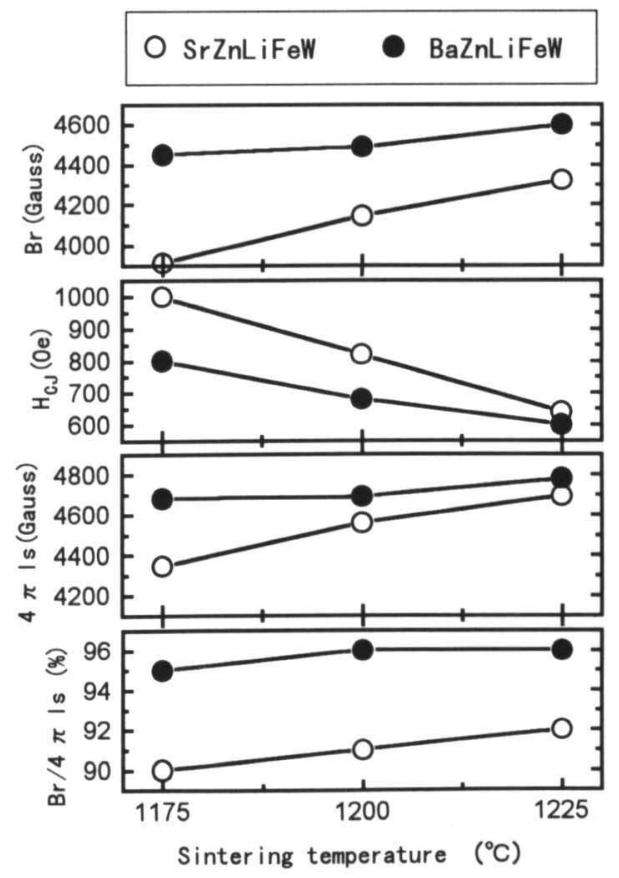

Fig.10 Various magnetic properties of SrZnLiFe $W$ and BaZnLiFe $W$ sintered in air.
Table 2 Anisotropy energy and anisotropy field of SrZnLiFe $W$ and BaZnLiFe $W$.

\begin{tabular}{|c|c|c|}
\hline $\begin{array}{c}\text { sintered at } \\
1200{ }^{\circ} \mathrm{C} \text { in } \\
\text { air.Composition }\end{array}$ & $\begin{array}{c}\mathrm{K}_{\mathrm{A}} \\
\left(\times 10^{6} \mathrm{erg} / \mathrm{cm}^{3}\right)\end{array}$ & $\begin{array}{c}\mathrm{H}_{\mathrm{A}} \\
(\mathrm{k} 0 \mathrm{e})\end{array}$ \\
\hline $\mathrm{SrZnLiFe} W$ & 2.3 & 12.3 \\
\hline $\mathrm{BaZnLiFe} \boldsymbol{W}$ & 2 & 10.3 \\
\hline $\mathrm{Sr} \boldsymbol{M}$ & 3.5 & 20 \\
\hline $\mathrm{Ba} \boldsymbol{M}$ & 3.3 & 17 \\
\hline
\end{tabular}

Table 3 Phase identified by X-ray diffraction and curie point for SrZnLiFe $W$ and $\mathrm{BaZnLiFe} W$ sintered at $1200^{\circ} \mathrm{C}$ in air.

\begin{tabular}{|c|c|c|}
\hline Composition & $\begin{array}{c}\text { Phase condition } \\
\text { by XRD }\end{array}$ & $\begin{array}{c}\text { Curie point } \\
\left({ }^{\circ} \mathrm{C}\right)\end{array}$ \\
\hline \multirow{3}{*}{ SrZnLiFe $W$} & & 435 \\
& & 460 \\
& & $>500$ \\
\hline BaZnLiFe $W$ & W & 425 \\
\hline
\end{tabular}

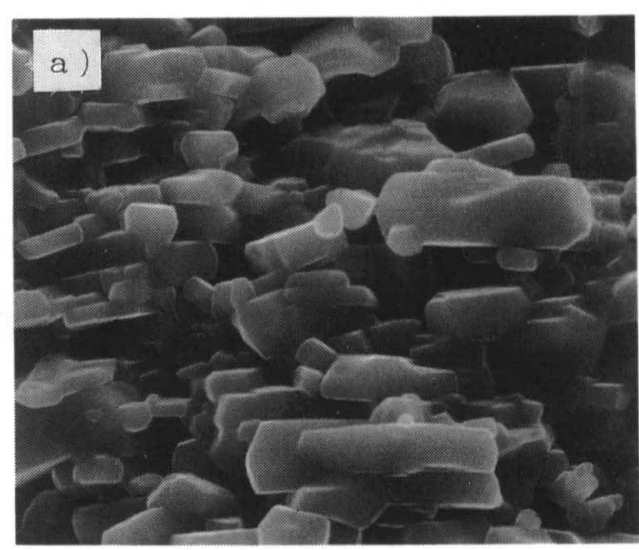

$\overline{2 \mu \mathrm{m}}$

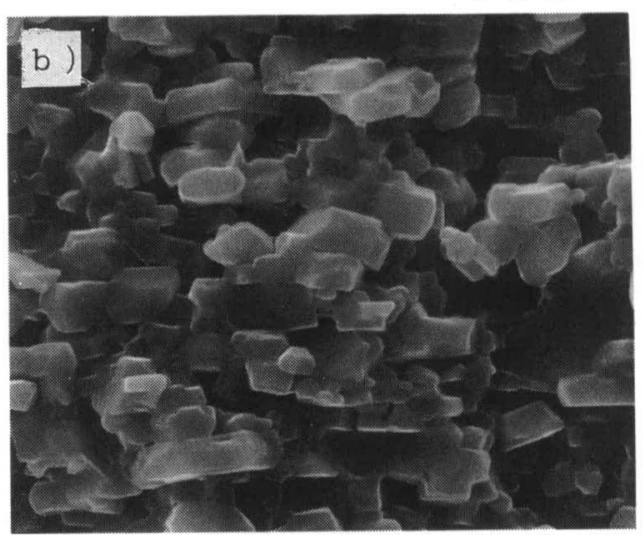
a) $\mathrm{SrZnLiFe} W$
b) BaZnLiFe $W$

Photo.1 SEM photograhs of SrZnLiFe $W$ and BaZnLiFe $W$ sintered at $1200^{\circ} \mathrm{C}$ in air. 


$$
4 \text { まと め }
$$

1) $\mathrm{Sr}_{1 \cdot \mathrm{xBaxZnLiFe} W} W$ 仮焼成材において, $\mathrm{X}=0$ で $\sigma \mathrm{s}=78 \mathrm{emu} / \mathrm{g} 、 \mathrm{BaZnLiFe} W$ $\sigma \mathrm{s}=73.5 \mathrm{emu} / \mathrm{g}$ とい う高い飽和磁化を持つW型フェライトが得られた.

2) Sr が多い組成において，仮焼成材を乾式粉砕 後, 空気中でアニールを行うと, $\mathrm{W}$ 相 $\rightarrow \mathrm{M}$ 相十スピネ ル相の相分解が生じた．また，焼結体においても $\mathrm{BaZnLiFe} W$ がW単相であったのに対し， $\mathrm{SrZnLiFe} W$ W相，M相，スピネル相の混相となっ た.

3） $\mathrm{Sr}$ 量が多い組成程，仮焼成材に存在する $\mathrm{Fe}^{2+}$ 量 が多く, 粉砕後の結晶歪みも大きい事がわかった。こ れらの事が，相分解に関与していると推察された.

4）異方性焼結磁石を作製した結果, 次の磁気特性が 得られた。

焼成温度 $1225^{\circ} \mathrm{C}$ 大気中焼成

$\mathrm{BaZnLiFe} W: \mathrm{Br}=4600 \mathrm{Gauss}, \mathrm{H}_{\mathrm{CJ}}=6000 \mathrm{e}$

SrZnLiFe $W: \mathrm{Br}=4320 \mathrm{Gauss}, \mathrm{H}_{\mathrm{C} J}=6400 \mathrm{e}$

SrZnLiFe $W$ の場合に Br が低いのは, 主に配向度

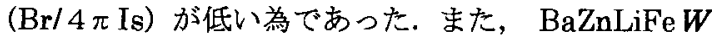
及び $\mathrm{SrZnLiFe} W$ $\mathrm{H}_{\mathrm{CJ}}$ が低いのは, $\mathrm{K}_{\mathrm{A}}, \mathrm{H}_{\mathrm{A}}$ がM 型の約 $60 \%$ と小さく，しかも粗大粒子が多く含まれ る為と考えられた.

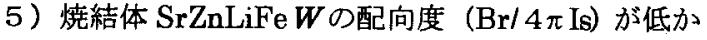
った原因としてスピネル相の生成と結晶歪みな どが考えられた。

\section{文 献}

1) J.Smit and H.P.J.Wijn : Ferrites , 177-211 (1959).

2）田口, 平田, 武石, 横山, 森 : 粉体および粉末治金, 39, (1992) 959.

3) H.Taguti, F.Hirata, T. Takeisi and T.Mori :

"Ferrites" Proceeding of ICF6, (1992) 1118.

4) F.K.Lotgering, P.H.G.M.Vromans and M.A.H.Huyberts : J.Appl.Phys. 51 (1980)

5) J.P.Mignot : J.Magn.Magn.Mater. 51, (1985) 337-341.

6) S.Ram and J.C.Joubert : J.Magn. Magn.Mater, 99, (1991) 133-144 .

7) 西尾 博明、田口 仁、山元 洋 : 電気学会各゙社仅双研究会資料, MAG-92-239, 9 (1992)

8 ) R.S.Tebble and D.J.Craik : Magnetic materials, (1969) 383. 